\title{
KIRGIZ TÜRKÇESİ İLE MOĞOLCA ARASINDAKİ ORTAK BİR EDAT 'ELE'
}

\section{Cüneyt AKIN*}

\section{Özet}

Kırgız Türkçesindeki Moğolca ortak unsurların bir kısmı Kırgız gramerlerinde belirtildiği halde, bazılarına yer verilmemiştir. Bu eklerden biri 'ele' edatıdır. Moğolcada bazı durumlarda 'la'/ 'le'ye değişen bu edat, ilgili kelimeden sonra gelerek, nitelediği kelimenin anlamını genelleştirmektedir. Çalışmada bu edatın Kırgız Türkçesindeki işlevleri ile Moğolcadaki işlevleri mukayese edilmiş ve hiçbir kaynakta Moğolcayla ortak unsur olduğu belirtilmeyen bu ekin ortaklı̆̆ tespit edilmiştir.

Anahtar Sözcükler: Kırgız Türkçesi, Moğolca, edat, ortak unsurlar.

\section{A COMMON PREPOSITION 'ELE' IN KYRGYZ TURKISH DIALECT AND MONGOLIAN LANGUAGE}

\begin{abstract}
In Kyrgyz Turkish grammar studies, some of the common elements with Mongolian are not included such as 'ele' preposition. This preposition, in Mongolian language, in some cases changes to '-la/-le' and generalizes the meaning of the word. In this study, the origin and usage of this preposition will be evaluated by comparing its functions both in Kyrgyz Turkish and Mongolian language. It is concluded that this preposition is common for both languages and common elements that are not mentioned in any source.
\end{abstract}

Keywords: Kyrgyz Turkish, Mongolian Language, partical, common elements.

\section{Giriş}

Atayurtları hakkında farklı görüşler bulunan Kırgızlar, bazı tarihçilere göre (V. V. Bartold ve A. N. Bernştam) ilk olarak Batı Sibirya, Yenisey ve Orhun Irmaklarının yukarı tarafları ile Altay ve Sayan dağlarında yerleşmişlerdir. Bir kısım tarihçiye (N. Y. Biçurin, Ç. Velihanov, N. A. Aristov) göre ise, Tanrı Dağları, Pamir Dağları, Altay Dağları, Isık-Köl ve Talas bölgesi Kırgızların ata yurdudur. Yukarıdaki görüşlerin bir sentezi ise, Yenisey-Batı Sibirya bölgesinde yaşayarak, daha sonra Altay ve Tanrı Dağları ile Talas bölgesine geldikleri şeklinde ifade edilmiştir (Erşahin, 1999: 395).

Yukarıdaki coğrafyalarda yaşayan Kırgızlar, yine bu bölgelerde yaşayan Moğol topluluklarıyla sürekli iletişim hâlinde, hatta özellikle Kırgızlar 'savaş' hâlinde yaşamışlardır. Bu gerçeğin izleri Manas destanının satırlarında açıkça görülmektedir.

Moğollarla asırlar boyu içli dışlı olan Kırgız Türkleri, bu süreçlerde Moğolcadan karşılıklı kelime ve gramer alıntıları yapmışlardır. Kırgız gramerlerinde Moğolca ile ortaklığı

\footnotetext{
* Yrd. Doç. Dr.; Afyon Kocatepe Üniversitesi, Fen Edebiyat Fak., Çağdaş Türk Lehçeleri ve Edebiyatları Bölümü, cuneyt.akin@ hotmail.com.
} 
belirtilen baz1 eklerin (Kudaybergenov ve Tursunov, 1980: 158; Oruzbayeva, 2000: 243-244; Kasapoğlu, 2005: 106, 112, 113) iki dil arasında ortak olan kelimeler dışında kullanılmadığına bakılırsa bu, eklerin değil kelimelerin ortaklığı olarak düşünülmelidir.

\section{Kırgız Türkçesi ve Moğolca arasındaki ortak unsurlar:}

Kırgız gramerlerinde Moğolca ile ortaklığı belirtilen ekler kısaca şöyledir: Moğolcada akrabalık derecesi adlarını ifade eden isimler yapan bir -nçar/-nçer eki (Yudahin, 1985: 241 togo+nçor maddesi; Poppe, 1992: 49). Moğolcadan girdiği düşünülen (Kudaybergenov,

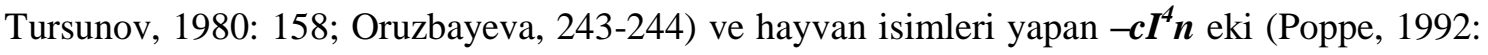
49; Kasapoğlu, 2005: 106; Eren, 2000: 47). Moğolca kaynaklı olduğu belirtilen (Orozbayeva, 2000: 242.) ve genellikle vasıf ismi yapan $+\boldsymbol{G A y} /+\boldsymbol{G O} \boldsymbol{y}$ eki (Kasapoğlu Çengel: 112-113). -l-

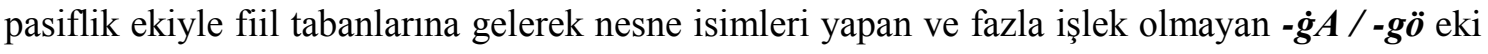
(Kırgiz gramerlerinde de -1lga / -ilge) (Orozbayeva, Kudaybergenov, 1964: 105. Oruzbayeva, 2000: 244; Kasapoğlu, 2005: 140-141; Poppe, 1992: 57). - lgA ekini Tuvacada da görmekteyiz (Bläsing, 2013: 11). Kırgız Türkçesinde sadece bir kelimede (cırga- 'mutlu ol-, haz duy-', cırga1 'mutlu, mutluluk') örneğini gördüğümüz (Kasapoğlu, 2005: 145) ve söz konusu fiil kökünden farklı isimler türeten bir $-l$ eki (Poppe, 1992: 57) $v b$. Yukarıdakiler dışında ortak unsurlardan da bahsedilmektedir: Poppe, 1992: 60, 71; Yudahin, 1985: 89; Korkmaz, 1988: 43-52; Tietze, 2002: 284; Sapjeyev, 1947: 376-382; Kasapoğlu, 2005: 216; Clauson, 1962: 219.

\section{2. 'ele' edatı:}

Divânu Lugati’t-Türk’te, işin tahakkukunu ve bitmesini gösteren bir edat olmak üzere fiillerin sonunda kullanıldığ belirtilmiştir: ol keldi-la 'o geldi be', ol bard-la 'o gitti-be' (DLT III: 213, 'la' maddesi). Ayrıca Besim Atalay bu ekle ilgili aynı maddeye düştüğü notta, ekin Orta ve Batı Anadolu'da: gelmesi şüpheli olan birini 'geldi le', okuması şüpheli olan, fakat okuyan birini ise, 'okudu le' ifadeleriyle, ahenksiz bir şekilde anlattığını ifade etmiştir.

Çağdaş Türk lehçelerinde ise bu yapının güçlendirici bir bağlaç olarak kullanıldığı görülmektedir: Alt. Bérgé lé 'lütfen ver', dürgéy lé 'bırak gitsin', Pir le kiji keldi 'Ancak bir adam geldi', Trkm. Mén işleyin le? 'Ben yapayım mı?', Hak. Çalgıs hartı̣a la aylahtançathan 'Yalnız bir kartal dönüp durdu'. Tat. Ay lé kåytmíym 'Ah, hayır dönmeyeceğim'vb. (Serebrenikov, Gadjiyeva, 2011: 212). Ayrıca bugünkü Türk lehçelerinden Altay, Başkurt ve Yeni Uygurcada edat olarak sınırlandırma işleviyle kullanılmaktadır. Yeni Uyg. emdi+la 'daha şimdi', birdin+la 'aniden', hemmi+la yerde 'her yerde', men+la emes 'sadece ben değil' $v b$. (Nadjip, 1968: 685). Altay Türkçesinde: peş+le 'sadece beş', emdi+le 'daha şimdi', pir+le 'sadece bir' (Verbitskiy, 1887: 196). Bu ek Kasapoğlu-Çengel tarafından Türkiye Türkçesindeki

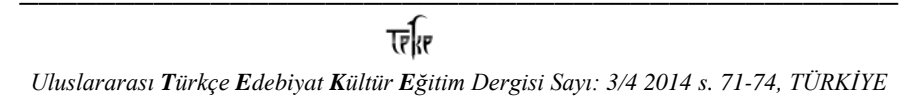

Iternational Journal of Turkish Literature Culture Education Volume 3/4 2014 p. 71-74, TURKEY 
'hele' ile paralel görülmüş ve 'özellikle', 'hiç olmazsa', 'her şeyden önce' anlamlarıyla cümle başı ve sonunda kullanıldığı belirtilmiştir: 'Dünyayı hele bir barış olsun da gör. Ayrıca, uyarma, korkutma ve vaat anlamlarıyla ve bir kelimeyi pekiştirmek amacıyla: Hele ba, neler diyor, Hele şükür vb. ifadelerde kullanılmıştır (Kasapoğlu, 2005: 347). Sınırlandırma işlevi Kırgız Türkçesindeki 'gana' edatıyla aynıdır (Kudaybergenov ve Tursunov, 1980: 513-514).

Kırgız Türkçesiyle Moğolcada kullanılan ve Kırgız gramerlerinde Moğolcayla ortaklığına değinilmeyen bir 'ele' edatı bulunmaktadır. Moğolcada bazı durumlarda 'la / le’ye değişen bu ek, Moğolcada ilgili kelimeden sonra gelerek, nitelediği kelimenin anlamını genelleştirmektedir: Mo. sayin ele keüked 'Umumiyetle iyi kızlar', tere ele çag -tur 'tam o anda' $v b$. Bu edat, herhangi bir anlam değişikliği oluşturmaksızın şart gerundiumu ile birleşmektedir: Mo. tere gacar-a iregsen abasu ele nököd inu ügei acuğu 'Oraya döndüğünde arkadaşları orada değildirler.' (Poppe, 1992: 243).

Kırgız Türkçesinde de bu ek, 'da, de, daha, sadece, öylesine' anlamlarını vermekte, cümlenin bütün öğelerinin sonuna gelerek, anlamı kuvvetlendirmektedir:

Çın ele bakıt değen uşul emespi? 'Gerçekten de mutluluk denen şey bu değil mi?

Bizdin oyubuzça mugalim degen bul cön ele kesip emes. 'Bize göre, öğretmenlik o kadar da basit bir meslek değil.'

Kara bak oşol kışka cakın bir tünü ele özünçö örttönüp ketti. 'Kara Bağ kışa yakın bir gece vakti öylece kendi kendine yanıp gitti.'

Kara taştı kaltırabızbı saga Şilbik? dedi Abdi özünçö ele bir nersege süyünüp. 'Kara taşı sana bırakır mıyız, Şilbik, dedi Abdi öylece kendi kendine bir şeye sevinerek.'

Küngö cetinçi janvar, biz cayı ele basılıp çıkkan cıynaktı karaptırmız. 'Bugün 7 Ocak, biz daha yeni basılmış olan dergiye bakıyoruz.

Al maga bügün bir tuuganday ele kımbat. 'O benim için kardeş kadar çok kıymetli.', Özüm ele keldim. 'Sadece ben geldim.'

Bu edat soru cümlelerinde cümle sonunda yer alarak şüphe edatı işlevinde de kullanılır. vb. (Kasapoğlu, 2005: 346-347).

Kasapoğlu-Çengel bu ekin Kırgızca şeklinin, ekin ön sesinde yer alan /e-/nin Kırgız Türkçesinde hikâye çekiminde kullanılan ele (< ede < edi) etkisiyle oluştuğu görüşündedir (Kasapoğlu, 2005: 347). Ancak, Moğolca şekil dikkate alındığında bu etkiyi tekrar düşünmek gerekecektir kanaatindeyiz. Yani, Kırgız Türkçesindeki 'ele' edatı ile hikâye çekimindeki 'ele' şekli muhtemelen birbiriyle bağlantılı değildir. Bu kanaate ulaşmamızda, Moğolcada edat 
görevinde kullanılan 'ele' ile Kırgız Türkçesinde edat görevindeki 'ele’nin ortaklığı bize fikir vermektedir.

\section{Kaynaklar}

BARTHOLD, V. V. Kırgızlar, Tarihi Oçerk, Kırgızdar II. (çev. D. Süleymankulov).

BERNŞTAM, A. N. Yenisey Kırgızdarınan Bizim Eraya Çeyin VI-X. Kılımlarda Koomduk Ekonomikalık Tüzülüşü, Kırgızdar II. (çev. M. Kocabekov).

BİÇURIN, N. Y. Bayırkı Mezgilde Orto Aziyada Caşagan Elder Turaluu Maalımattardın Clynagl, Kizgizdar-I.

BLÄSING, U. (2013). Batalga'dan Çökelge'ye Anadolu Ağızlarındaki -alga/-elge Ekine Dair. Dil Araştırmaları, 13, 9-36.

EREN, H. (2000). Türkçede Moğolca Kalıntılar [Claus Schönig, Mongolische Lenwörter im Westogusischen Wiesbaden, VI+210 Turcologica 47].

ERGIN, M. (1970). Orhun Abideleri. İstanbul: Boğaziçi Yayınları.

ERŞAHIN, S. (1999). Kırgızların İslamlaşması Üzerine Bazı Mülahazalar. Ankara Üniversitesi Ilahiyat Fak. Dergisi, 39, 1.

GABAIN, A. V. (1988). Eski Türkçenin Grameri. (çev. Mehmet Akalın). Ankara.

GÜNGÖRDÜ, E. (2002). İsimden Fiil Türeten +ç1-/+çi- Eki ve Gelişmiş Şekilleri. Gazi Eğitim Fakültesi Dergisi, 22, (3).

KASAPOĞLU ÇENGEL, H. (2005). Kırgız Türkçesi Grameri-Ses ve Şekil Bilgisi. Ankara: Akçağ Yayınları.

KORKMAZ, Z. (1988). Türkçe ile Moğolca Arasında Ortaklaşan Unsurlar ve Mogolcanın Türk Dili Araştırmalarındaki Yeri. Ankara: TDAY-B.

KUDAYBERGENOV, S. ve TURSUNOV, A. (1980). Kırgiz Adabiy Tilinin Grammatikası, Fonetika cana Morfologiya. Frunze.

OROZBAYEVA, B. Ö. (2000). Kırgız Tilindegi Kurandı Müçölör, Söz Kuramı. Bişkek.

OROZBAYEVA, B. Ö. ve KUDAYBERGENOV, S. (1964). Kırgız Tilinin Grammatikası, Morfologiya. Frunze, 105.

POPPE, N. (1992). Moğol Yazı Dilinin Grameri. (çev. Günay Karaağaç). İzmir: Ege Üniversitesi Basımevi.

SEREBRENIKOV, B. A. ve GADJIYEVA, N. Z. (2011). Türk Yazı Dillerinin Karşılaştırmalı Tarihî Grameri. (çev. Tevfik Hacıyev, Mustafa Öner). Ankara.

TEKIN, T. (1988). Orhon Yazıtları. Ankara: Türk Dil Kurumu Yayınları.

TEKİN, T. (2000). Orhun Türkçesi Grameri. Ankara: Simurg Yayınları.

TIETZE, A. (2002). Tarihi ve Etimolojik Türkiye Türkçesi Lugatı. İstanbul: Simurg Yayınları.

TURSUNOV, A. (1980). Kirgız Adabiy Tilinin Grammatikasl, Fonetika cana Morfologiya. Frunze,

VERBITSKIY, V. (1887). Slovar'Altayskogo i Aladagskogo Nareçiy Tyurskogo Yazıka. Kazan.

YUDAHİN, K. K. (1998). Kırgız Sözlüğü. (çev. Abdullah Taymas). Ankara: Ankara Üniversitesi Basımevi. 